\title{
Influence of Sn on Practical Performances of Structural Steels
}

\author{
Kazuki Inujima ${ }^{1}$, Kazutoshi Ichikawa ${ }^{2}$ \\ ${ }^{1}$ Graduate school of environmental studies, Tohoku University \\ 2-1-1 Katahira, Sendai, Japan \\ kazuki.inujima.s5@dc.tohoku.ac.jp; kazutoshi.ichikawa.b6@tohoku.ac.jp \\ ${ }^{2}$ Graduate school of environmental studies, Tohoku University \\ 2-1-1 Katahira, Sendai, Japan
}

\begin{abstract}
Some organisations are now considering further use of "recycled steel" to reduce environmental impacts because they believe such steel may contribute to reduce $\mathrm{CO}_{2}$ emission compared with steel made of iron ores. In the case of "recycled steel" however, impurity concentration may increase if they are made of low-quality recycled materials; especially some elements such as $\mathrm{Cu}$ and $\mathrm{Sn}$ are difficult to remove from steels. These elements are called as "tramp elements" and there even is a report that concentrations of these elements in scrap are increasing recently [1]. "Recycled steel" steels are often used for structural steels (i.e., for constructions) which should have high strength, toughness and weldabilities. Sn is particularly well-known as a detrimental element for structural steels. Therefore, it is important to identify the influence of Sn on mechanical properties of structural steels.

5 casted steels with different $\mathrm{Sn}$ concentration are rolled into $75 \mathrm{~mm}$ thick plates and water-cooled in this study, Mechanical properties, such as strength, ductility and Charpy toughness, are then examined in the directions of length and width for all the plates. Furthermore, characteristics of thickness direction are also investigated to evaluate lamellar tear susceptibility, which is a weld flaw. In addition, microstructures and ferrite matrix hardness are measured and investigated to discuss the influence and mechanisms of $\mathrm{Sn}$ on the mechanical properties of steels. As the results, yield and tensile strength and absorbed energy in $20^{\circ} \mathrm{C}$ are decreased and fracture appearance ductile to brittle transformation temperature (FATT) is increase with the increase in Sn. Toughness (FATT and absorbed energy) in thickness direction are particularly deteriorated by Sn. It can be assumed that, according to the considerations on tensile and hardness test results, strengthening and deterioration in toughness by Sn are due to solid solution strengthening.
\end{abstract}

Keywords: Recycled steel, Mechanical properties, Thickness direction, Tin, Environmental impacts, SDGs

\section{Introduction}

Steel is practically only a material on which "closed-loop-recycle" can be applied. Where "closed-loop-recycle" is a infinite and versatile recycling system which can reproduce variety of new products from scrap [2]. One of the reasons of that steel can be a closed-loop-recycle material is that tramp elements in steels can be managed fairly easily, compared with other metals. Where "tramp elements" can be defined as elements which are difficult to be removed by refining processes. Closed loop recycle can realise in fact more sustainability than so-called "open-loop-recycle system" through reducing natural resources consumption. This system plays thus important roles to realize "responsible consumption" as one of SDGs (Sustainable Development Goals) which was defined by United Nations [3]. Some refers "recycled steel" as electric furnace steel since they controversially believe it is more environmentally friendly material, because conversion process from iron ore to crude iron in blast furnace occupied more than $70 \%$ of carbon dioxide emissions in Japan for example [4]. Tokyo metropolitan government, Japan then considers further use of "recycled steel" for public constructions [5]. There are also some other countries considering similar policy [6]. These expansions of the use of "recycle steel" have to be carefully verified in the view of materials science and structural safety, however.

In steel (particularly "recycled" one), $\mathrm{Cu}, \mathrm{Ni}, \mathrm{Mo}$ and $\mathrm{Sn}$ are contained as "tramp elements" for example. Small amount of increase in $\mathrm{Cu}$ is less detrimental for steel mechanical property and $\mathrm{Ni}$ and Mo may be rather beneficial because they sometimes improve strength and toughness of steel. Meanwhile, Sn is reported as detrimental for mechanical properties such as strength and toughness of steel [7] [8]. Sn, as well as $\mathrm{Cu}$, in scraps as iron source is reported as gradually increasing in fact which may be needed to be gave attention [1]. "Recycled steel" is often used for building structural in Japan [9], which have to have sufficient strength, ductility and toughness because Japan have many disasters such as earthquake. Therefore, it is important to identify the influence of changing the concentration of Sn on mechanical properties of structural steel.

In this study then influence of Sn on practical performances of structural steels was investigated. The practical performance includes mechanical properties, such as include strength and toughness in the variety of directions and locations in plate. To estimate the influences on lamellar tear of welding [9], characteristics of thickness direction was 
measured in each case particularly. The strengthening mechanism was discussed as well, according to the microstructures and microhardness.

\section{Experiment procedures}

\subsection{Base materials}

5 steel ingots were casted by $300 \mathrm{~kg}$ vacuum furnace. Their chemical compositions are shown in Table 1 . These ingots, which nominal thickness are $265 \mathrm{~mm}$, were reheated at $1200^{\circ} \mathrm{C}$, rolled into $75 \mathrm{~mm}$-thick plates via 14 pass rollings and water-cooled. Water cooling started at about $830^{\circ} \mathrm{Cdown}$ to about $550^{\circ} \mathrm{C}$.

Table 1: Chemical compositions of each steels (mass\%).

\begin{tabular}{|c|c|c|c|c|c|c|c|c|c|c|c|c|}
\hline Code & $\mathrm{C}$ & $\mathrm{Si}$ & $\mathrm{Mn}$ & $\mathrm{S}$ & $\mathrm{P}$ & $\mathrm{Cr}$ & $\mathrm{Ni}$ & $\mathrm{Cu}$ & $\mathrm{Al}$ & $\mathrm{Sn}$ & $\mathrm{N}$ & $\mathrm{O}$ \\
\hline SN1 & 0.15 & 0.28 & 1.20 & 0.0030 & 0.015 & 0.096 & 0.097 & 0.18 & 0.020 & $<0.0003$ & 0.0102 & 0.0014 \\
\hline SN2 & 0.15 & 0.30 & 1.22 & 0.0029 & 0.016 & 0.097 & 0.099 & 0.18 & 0.021 & 0.019 & 0.0097 & 0.0014 \\
\hline SN3 & 0.15 & 0.30 & 1.19 & 0.0031 & 0.015 & 0.097 & 0.099 & 0.19 & 0.020 & 0.050 & 0.0101 & 0.0016 \\
\hline SN4 & 0.16 & 0.29 & 1.17 & 0.0030 & 0.015 & 0.097 & 0.098 & 0.19 & 0.019 & 0.100 & 0.0104 & 0.0016 \\
\hline SN5 & 0.16 & 0.30 & 1.20 & 0.0032 & 0.014 & 0.100 & 0.100 & 0.21 & 0.020 & 0.300 & 0.0103 & 0.0018 \\
\hline
\end{tabular}

\subsection{Mechanical tests}

All steel samples were provided for tensile and Charpy impact tests. Sampling locations and directions are shown in Fig.1. 2 samples for tensile tests and 75 samples for Charpy impact tests were machined for each location and direction. Directions are defined as "L", "C" and "Z", which denote length, width and thickness directions respectively.as shown in Fig.1. Sampling locations are (1/2)t and (1/4)t, where $t$ is the plate thickness. In this study, thickness direction was particularly considered to evaluate the influences of $\mathrm{Sn}$ on lamellar tear susceptibility, one of the flaws of welding, which may occur heavy section plate welds as Fig.2. In this case, rolling direction is along with length direction. The specimen details for tensile tests are $32 \mathrm{~mm}$ gage length and $6 \mathrm{~mm}$ diameter with $70 \mathrm{~mm}$ specimen length. $2 \mathrm{~mm}-\mathrm{V}$ notched Charpy impact test was carried out with 5 temperatures which consist of at least common

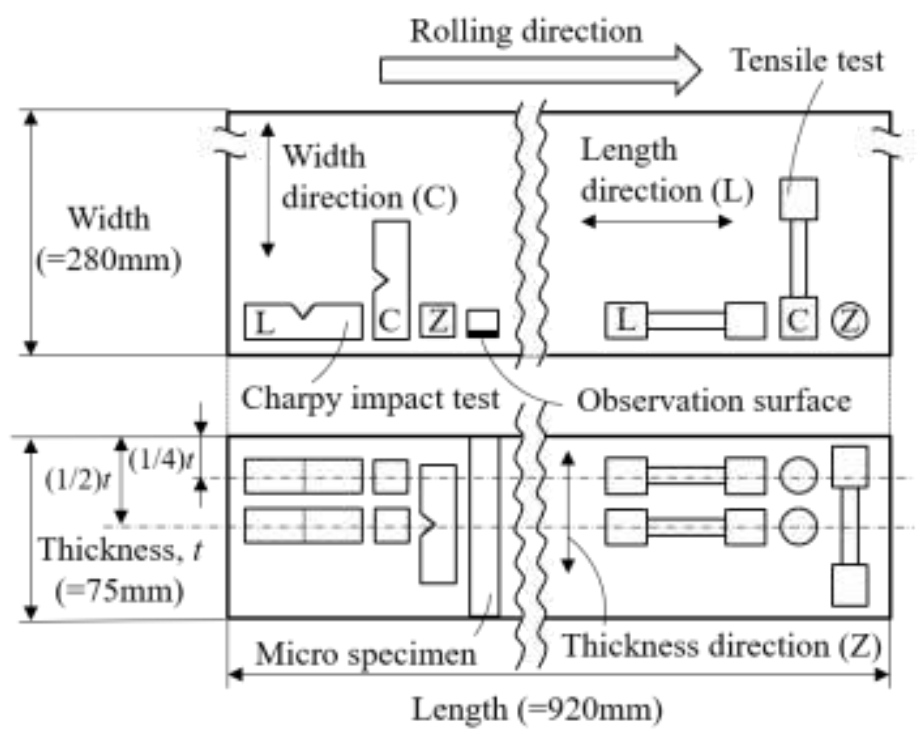

Fig. 1: Specimen sampling locations and directions. temperature of $20{ }^{\circ} \mathrm{C}$ and 4 other temperatures chosen from the range of 0 to $80{ }^{\circ} \mathrm{C}$ with 3 repetitions for each temperature. Crystallinities (percent crystalline or brittle fracture surface), to determine fracture appearance ductile to brittle transformation temperatures (FATTs), were measured as well as absorbed energy of each Charpy impact specimen.

\subsection{Microstructure observation and micro-Vickers tests}

Through thickness (i.e., $75 \mathrm{~mm}$ ) samples for microstructure observation were collected from each steel plate with the observation plane (longitudinal vertical plane to the rolling direction) shown in Fig.1. Microstructure

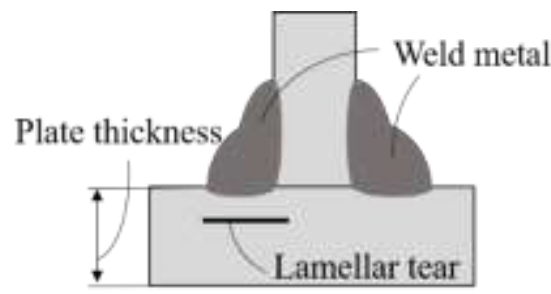

Fig. 2: Schematic image of lamellar tear in welds. observation positions include (1/4) $t$ and , (1/2)t with an etching agent of $2 \%$ Nital. All microstructure samples were also subjected for micro-Vickers tests to evaluate hardness of ferrite grain matrix without grain boundary effects, which cannot identify by tensile tests or ordinary Vickers hardness tests. The test load was $10 \mathrm{gf}$ with keeping time of 12 seconds. 10 ferrite grains were selected, which locate around (1/2)t, and measured. Furthermore, in order to investigate the constitutions of various microstructures in steels, metallographic tests were also applied. "Point 
counting technique" was adopted here, where 100 points of the microstructures were determined visually on the optical micrographs taken with the magnification of 200 .

\section{Results and Discussions}

\subsection{Strength}

Fig. 3 and Fig. 4 show the effects of Sn on proof and tensile strength respectively. Both proof and tensile strengths in $(1 / 4) t$ are higher than those in (1/2) $t$ in both $\mathrm{L}$ (longitudinal) and C (width) directions. Tensile properties of Z (platethickness direction) show similar tendency to those of longitudinal (L) and width (C) direction at the thickness centre (i.e., $(1 / 2) t)$. It is quite reasonable because gage length region of a $\mathrm{Z}$ direction tensile specimen locates in thickness centre. It can be assumed that the difference in the strength between (1/2)t and (1/4) $t$ owe to the difference in cooling performance; i.e., cooling rate shall be higher at $(1 / 4) t$ than one at $(1 / 2) t$ particularly for heavy section materials applied in this study. It should be mentioned that the strengths do not depend on specimen direction (L, C and Z) in large extent but do well on the sampling location in thickness direction in the present study cases.

It has to be noted that, from Fig. 3 and Fig.4, the initial rises in proof and tensile strength is steep while the subsequent rises in these are moderate. It is therefore assumed that these are reasonably approximated by a parabolic function. Proof and tensile strength are then plotted as a function of square root of Sn concentration in Fig.5 and Fig.6 respectively. As shown in these figures, it is demonstrated that the square root of Sn concentration and the strengths are in linear relationship. This will be discussed in detail later in this paper with the micro-Vickers hardness results.

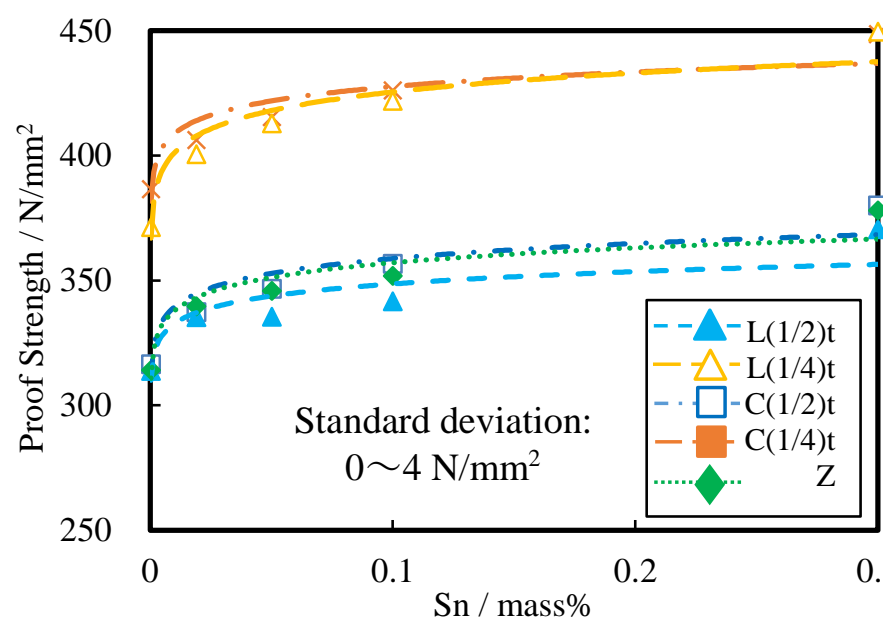

Fig.3: Influence of Sn concentration on proof strength

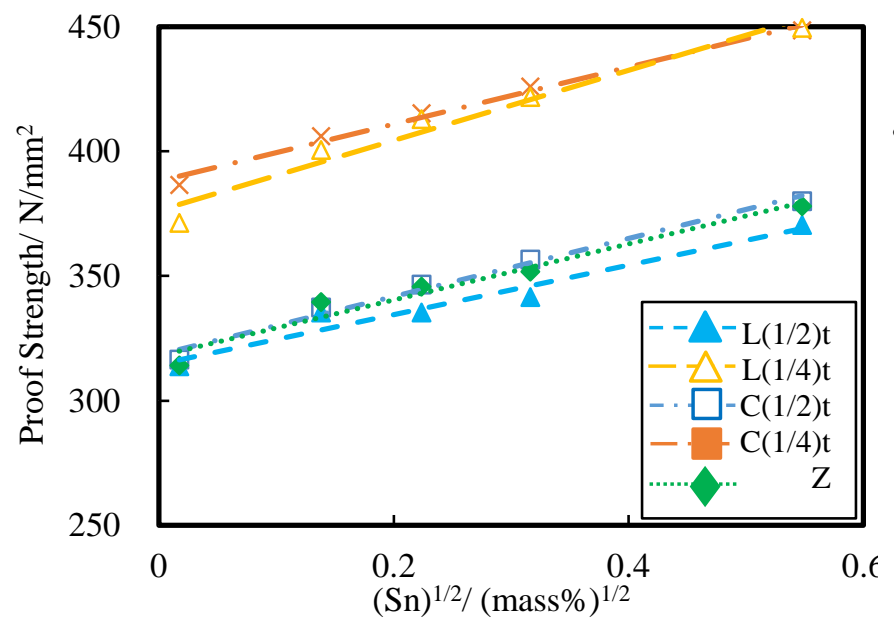

Fig. 5: Relationship between square root of $\mathrm{Sn}$ concentration and proof strength.

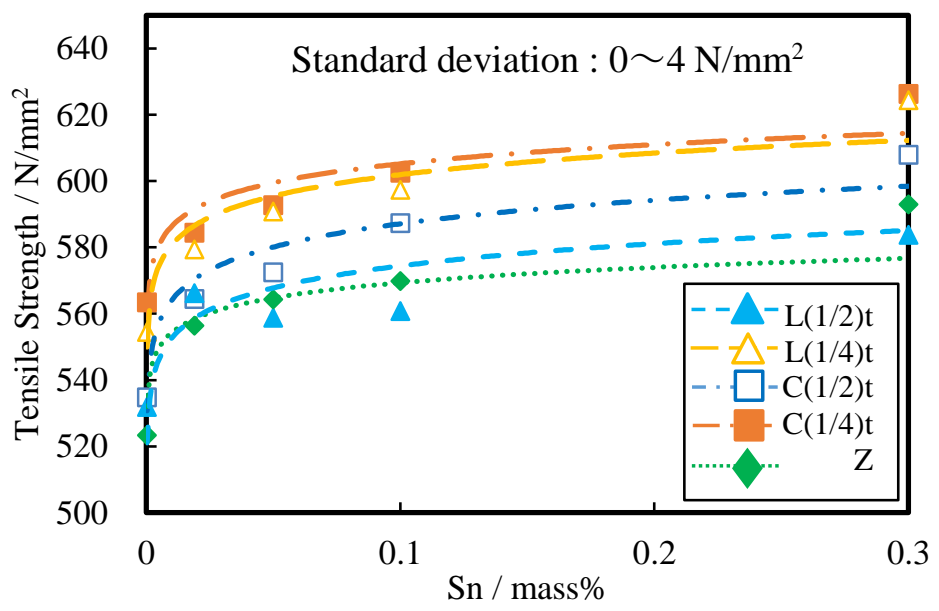

Fig.4: Influence of Sn concentration on tensile strength.

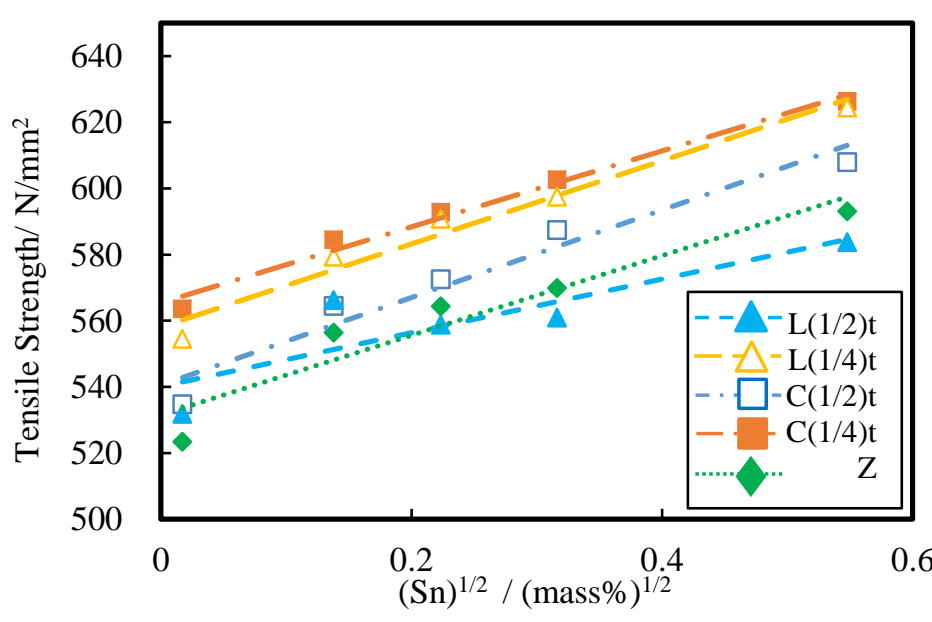

Fig. 6: Relationship between square root of $\mathrm{Sn}$ concentration and tensile strength. 


\subsection{Charpy impact toughness}

Fig7 shows influence of Sn concentration on FATT. FATT increases with Sn concentration in all directions and locations and their relationship can be roughly approximated by the parabolic lines. For all directions and locations, except for thickness direction, they demonstrated almost fairly similar movements of the values of FATT against $\mathrm{Sn}$ concentration. FATT in thickness direction is however apparently inferior to any other directions and locations. Fig.8 shows the relationship between absorbed energy and Sn concentration at $20^{\circ} \mathrm{C}$. Like FATT, the absorbed energy increases with Sn concentration in all directions and locations and their relationship can be roughly approximated by the parabolic lines. For all directions and locations, except for thickness direction, they demonstrated almost fairly similar tendencies of absorbed energy as the functions of $\mathrm{Sn}$ concentration. Toughness represented by Charpy impact test such as FATT and absorbed energy can be often related with the strength. Relationship between tensile strength and FATT is then shown in Fig.9. FATT shown in Fig.7 can be represented as the functions of the tensile strength. Therefore, it can be assumed that toughness (e.g., FATT and absorbed energy) are also in parabolic relationship with Sn concentration, which is similar to proof and tensile strengths, because toughness shows linear relationship with strength.

As written in above, FATT can be represented as the functions of the strength. Since FATTs were deduced by several measurements of the fracture surfaces however and thus may contain larger intrinsic error than definite absorbed energy. It is thus more evident in the parabolic relationship between Sn concentration and toughness if it is demonstrated by absorbed energy as shown in Fig. 8. Fig.10 shows the relationship between absorbed energy and tensile strength.
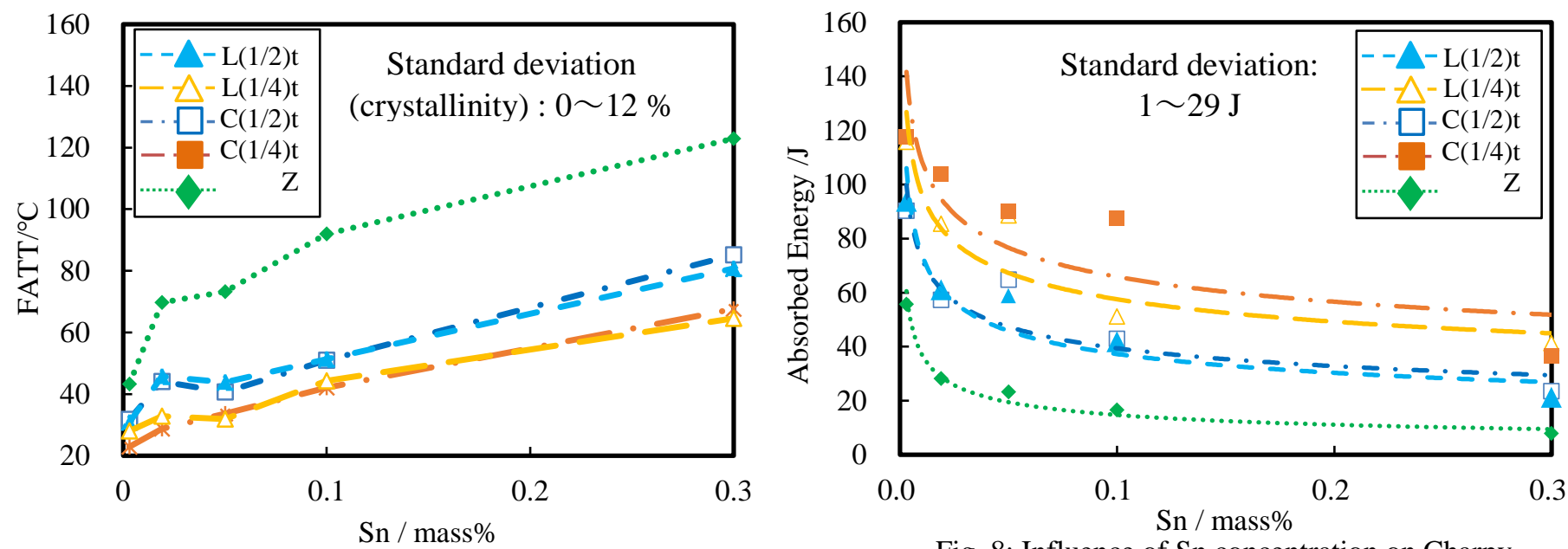

Fig. 7: Influence of Sn concentration on FATT.

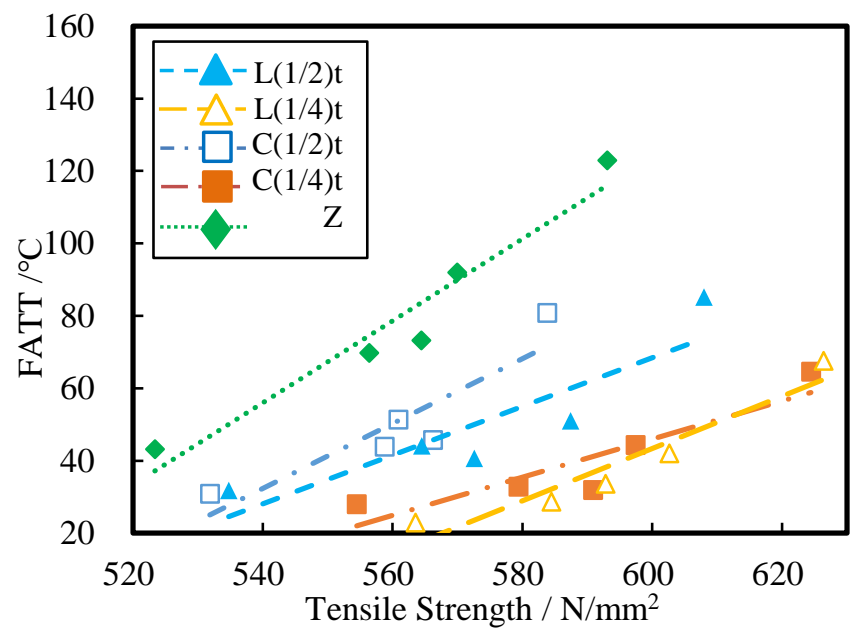

Fig. 9: Relationship between tensile stress and FATT.

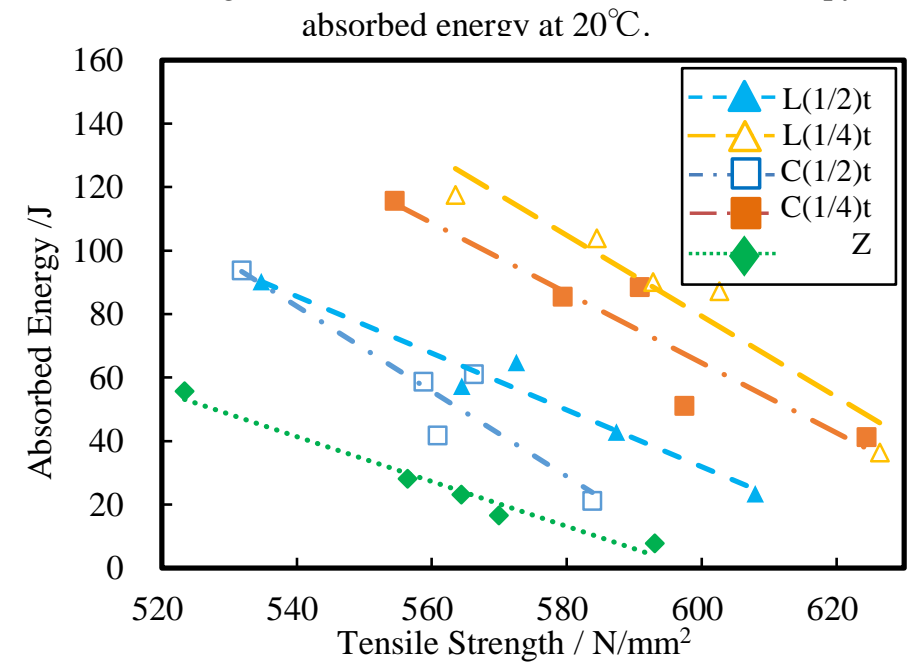

Fig. 10: Relationship between tensile strength and Charpy absorbed energy at $20^{\circ} \mathrm{C}$. 
These figures (Fig.8 and Fig. 10) indicate that absorbed energy value can also be represented as the functions of the tensile strength. In addition, absorbed energy in thickness direction is particularly inferior to any other directions and locations. Therefore, Sn causes a detrimental influence on both FATT and absorbed energy. In particular, this trend is prominent in the thickness direction of Charpy test specimen. This must negatively affect lamellar tear of welding in heavy section plates by even slight contains of Sn.

\subsection{Strengthening mechanisms}

Fig.11 and 12 shows microstructures at (1/2)t and surface of SN1 respectively. The steel at (1/2)t contains larger grains of ferrite with minor amount of pearlite, bainite and Widmanstätten ferrite, while one at surface does mainly bainite.. This difference in the microstructures causes the higher tensile and proof strengths in the longitudinal and width directions at (1/4) $t$ than those in the same directions at (1/2)t, (and $\mathrm{Z}$ directions as well) as demonstrated in 3.1.

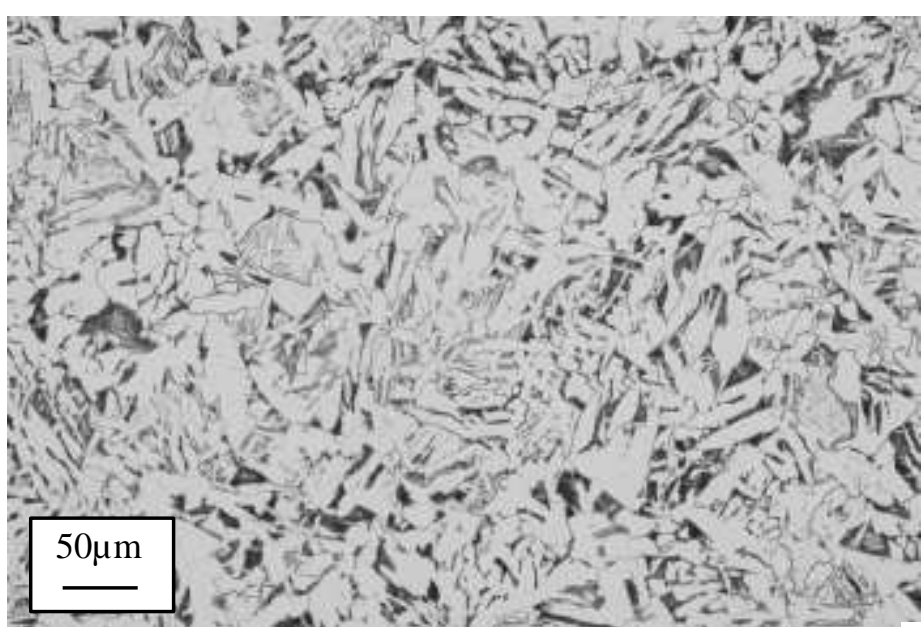

Fig. 11: Microstructure of SN1 at $(1 / 2) t$, where $t$ is plate thickness.

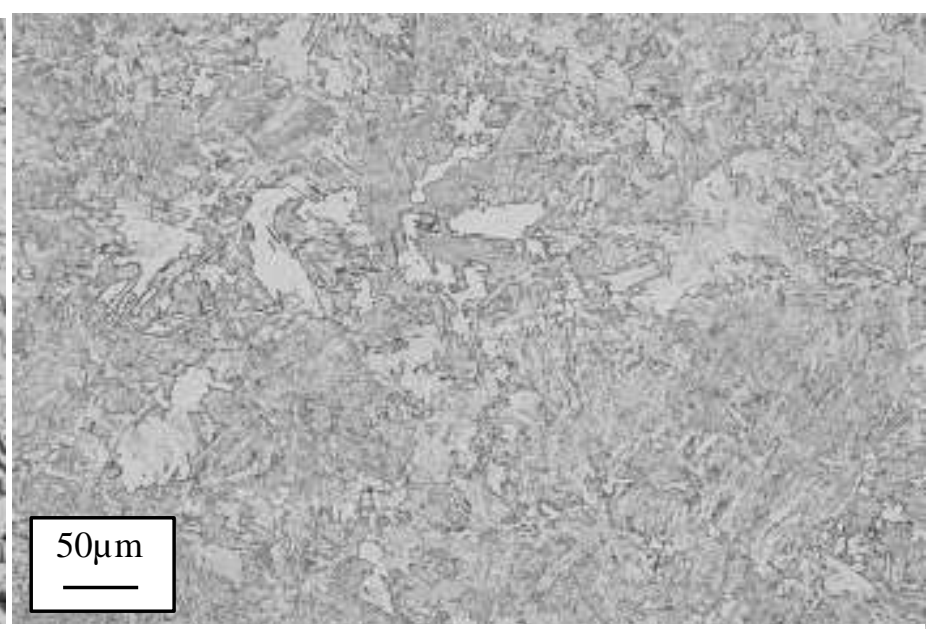

Fig. 12: Microstructure of SN1 at surface.

As seen in Fig.5 and Fig.6, strength in all directions and locations exhibit parabolic relationship with Sn concentration. It suggests that strengthening mechanism may be explained by solid solution strengthening because such mechanism is well known to be represented by the format of equation (1) for example [10].

$$
\sigma_{1} \cong M \alpha G \sqrt{c}
$$

where $\sigma_{1}$ is yield strength, $M$ is Taylor factor, $\alpha$ is interaction parameter $(0<\alpha<1)$ between matrix and solution atoms as a function of the difference in the atomic radiuses and the "distance" in the periodic table, $G$ is shear modulus and $c$ is alloy concentration. This equation can be simplified to the expression of equation (2) where $k$ is constant independent to $c$.

$$
\sigma_{1} \cong k \sqrt{c}
$$

The results of the point counting are shown in Fig.13. Considering the nature of the quantitative technique of this microstructural experiment, there seems to see no significant difference in the constitution of microstructure, except no existence of Widmanstätten ferrite in $0.003 \%$ (SN1). only these minor difference in microstructure shown in Fig. 13 cannot explain the increase in strength shown in Fig.3 and Fig.4. It thus can be assumed that microstructural change by $\mathrm{Sn}$ is not a major factor controlling the strength.

Then, to see the mechanism of strength increase by Sn in the steels, Fig.14 shows the relationship between average micro-Vickers hardness of 10 ferrite grain matrices and Sn concentration, where the error bars are lined between maximum and minimum values. It seems that the microhardness of ferrite matrix exhibits parabolic relationship with $\mathrm{Sn}$ concentration, similar to strength represented in Fig. 3 and 4. According to these experimental results, major strengthening mechanism by $\mathrm{Sn}$ is determined as solid-solution strengthening. This is in fact a quite useful and important assumption because it suggests that detrimental influence of Sn on mechanical properties can be minimised by reducing 


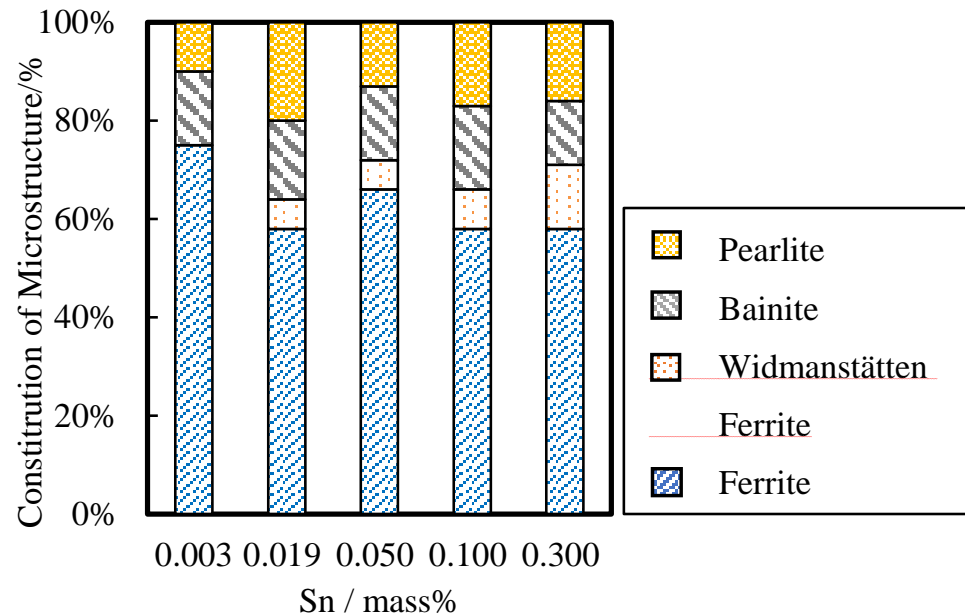

Fig. 13: Influence of Sn concentration on microstructural constitutions at $(1 / 2) t$, where $t$ is plate thickness.

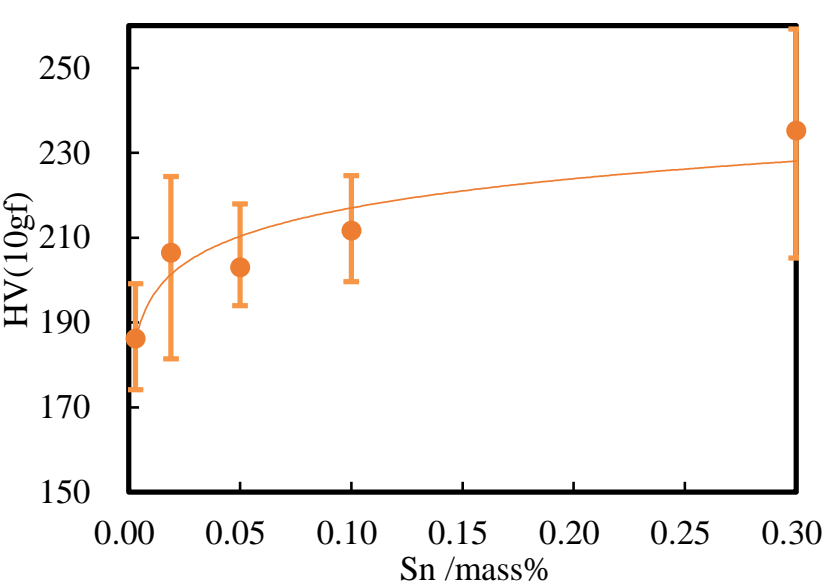

Fig. 14: Relationship between Sn concentration and hardness of ferrite matrix.

strength by decreasing other alloy elements concentration such as $\mathrm{Mn}$. An important unsolved issue raised in this study is the mechanism of the prominent deterioration of the toughness of $\mathrm{Z}$ direction (thickness direction) with $\mathrm{Sn}$ concentration. It should be noted however that grain boundary embrittlement by $\mathrm{Sn}$ has to be investigated carefully to discuss the effect of $\mathrm{Sn}$ on toughness. Further careful investigations on the microstructural and crystallographic anisotropies should be needed.

\section{Conclusions}

As the results of present study on the influence of Sn, as a tramp element in heavy section steel, on the mechanical properties, it was identified that Sn (up to 0.300 mass $\%$ ) causes some detrimental influences on practical performances of structural steel as following.

(1) Proof and tensile strengths are increased with Sn concentration increases in all directions includes plate longitudinal, width and thickness directions. These strengths are in parabolic relationships with Sn concentration.

(2) Toughness, represented by fracture appearance ductile and brittle transition temperature (FATT) and Charpy absorbed energy, are deteriorated by Sn concentration increase. It is in proportional relationship with strength. It is thus assumed that toughness is also in parabolic relationship with Sn concentration. In addition, the toughness in thickness direction is particularly inferior to one in other directions (plate longitudinal and width directions).

(3) According to the above and micro-Vickers hardness test results, it is assumed that major strengthening mechanism by $\mathrm{Sn}$ in this study is solid-solution strengthening.

As mentioned in (2), Sn, which may come from scrap, contained heavy section structural steels may seriously affect the safety of structures through lamellar tear while welding and toughness deterioration. Therefore, it is important to be careful to increase Sn concentration of structural steel. 


\section{References}

[1] Tokyo Steel, Report of investigations on extensive utilisation of steel scrap in fiscal year 2013 (in Japanese) [Online]. Available: http://www.env.go.jp/recycle/car/pdfs/h25_report05_mat01.pdf

[2] T. Isohara," Life Cycle Assessment in Steel Products," ISIJ Int., vol. 45, pp. 1-28, 2018.

[3] United Nations, "Sustainable Development Goals." [Online]. Available: https://www.un.org/sustainabledevelopment/sustainable-development-goals/

[4] T. Ariyama, R. Murai, J. Ishii and M. Sato," Reduction of CO2 Emissions from Integrated Steel Works and Its Subjects for a Future Study," ISIJ Int., vol. 45, pp. 1371, 2005

[5] Tokyo metropolitan government, Tokyo metropolitan government procurement policies for environmental articles in fiscal year of 2007 (in Japanese) [Online]. Available: http://www.toshiseibi.metro.tokyo.jp/seisaku/recy/pdf/recy_29-1.pdf

[6] Mitsubishi Research Institute, Investigations on future advancement of electric furnace steel industry in 2011, (in Japanese) [Online]. Available: www.bpfj.jp/act/download_file/78638529/18603727.pdf

[7] B. Liu and Y. F. Zheng, "Effects of alloying elements (Mn, Co, Al, W, Sn, B, C and S) on biodegradability and in vitro biocompatibility of pure iron," Acta Biomaterialia., vol. 7, pp. 1407-1420, 2011.

[8] S. Shenghua, X. Yewei, C. Xianmiao and J. Xue," Effect of rare earth cerium and impurity tin on the hot ductility of a Cr-Mo low alloy steel," Journal of rare earths., vol. 34, no. 10, pp. 1062-1068, 2016.

[9] H. Furuya, R. Uemori, S. Aihara, Y. Tomita, T. Ikebe, T. Kojima, H. Okamoto, T. Kubo, R. Ando, K. Higuchi, A. Mukai and K. Morita, "Effect of Chemical Compositions of the HAZ Toughness and Its Formulation under Simulated Column-Beam Connection Welding of Structual Steel for Building," Steel Construction Engineering, vol. 8, pp. 17-31, 2001.

[10] K. Maruyama, M. Fujiwara and K. Yoshimi, Kouzou Kinzoku Zairyou Gaku. Uchidarokakuho publishing co., ltd, 2014 